OPEN ACCESS

Edited by:

Steffen Stenger,

Universitätsklinikum UIm,

Germany

Reviewed by:

Maria Florencia Quiroga,

Universidad de Buenos

Aires, Argentina

Elsa Anes,

Universidade de Lisboa, Portugal

*Correspondence:

Mariateresa Coppola

m.coppola@/umc.nl

${ }^{t}$ Present address:

Tom P. Gillis,

Research Chair, The Leprosy

Mission Canada, Markham,

ON, Canada

FThese authors have contributed equally to this work.

Specialty section:

This article was submitted to

Microbial Immunology,

a section of the journal

Frontiers in Immunology

Received: 09 November 2017 Accepted: 05 February 2018

Published: 26 February 2018

Citation:

Coppola M, van den Eeden SJF, Robbins N, Wilson L, Franken KLMC,

Adams LB, Gillis TP, Ottenhoff THM and Geluk A (2018) Vaccines for

Leprosy and Tuberculosis:

Opportunities for Shared Research,

Development, and Application.

Front. Immunol. 9:308.

doi: 10.3389/fimmu.2018.00308

\section{Vaccines for Leprosy and Tuberculosis: Opportunities for Shared Research, Development, and Application}

\author{
Mariateresa Coppola ${ }^{1 *}$, Susan J. F. van den Eeden', Naoko Robbins' ${ }^{2}$, Louis Wilson', \\ Kees L. M. C. Franken ${ }^{1}$, Linda B. Adams ${ }^{2}$, Tom P. Gillis ${ }^{2 \dagger}$, Tom H. M. Ottenhoff ${ }^{1 \neq}$ and \\ Annemieke Geluk ${ }^{1 \neq}$ \\ ${ }^{1}$ Department of Infectious Diseases, Leiden University Medical Center, Leiden, Netherlands, ${ }^{2}$ The National Hansen's \\ Disease Programs, Baton Rouge, LA, United States
}

Tuberculosis (TB) and leprosy still represent significant public health challenges, especially in low- and lower middle-income countries. Both poverty-related mycobacterial diseases require better tools to improve disease control. For leprosy, there has been an increased emphasis on developing tools for improved detection of infection and early diagnosis of disease. For TB, there has been a similar emphasis on such diagnostic tests, while increased research efforts have also focused on the development of new vaccines. Bacille Calmette-Guérin (BCG), the only available TB vaccine, provides insufficient and inconsistent protection to pulmonary TB in adults. The impact of BCG on leprosy, however, is significant, and the introduction of new TB vaccines that might replace BCG could, therefore, have serious impact also on leprosy. Given the similarities in antigenic makeup between the pathogens Mycobacterium tuberculosis (Mtb) and M. leprae, it is well possible, however, that new TB vaccines could cross-protect against leprosy. New TB subunit vaccines currently evaluated in human phase I and II studies indeed often contain antigens with homologs in $M$. leprae. In this review, we discuss pre-clinical studies and clinical trials of subunit or whole mycobacterial vaccines for TB and leprosy and reflect on the development of vaccines that could provide protection against both diseases. Furthermore, we provide the first preclinical evidence of such cross-protection by Mtb antigen 85B (Ag85B)-early secretory antigenic target (ESAT6) fusion recombinant proteins in in vivo mouse models of Mtb and $M$. leprae infection. We propose that preclinical integration and harmonization of TB and leprosy research should be considered and included in global strategies with respect to cross-protective vaccine research and development.

Keywords: antigen 85B, early secretory antigenic target, Mycobacterium leprae, Mycobacterium tuberculosis, tuberculosis, leprosy, hybrid recombinant protein, vaccines

\section{INTRODUCTION}

Tuberculosis (TB) and leprosy are major infectious diseases that are caused by highly related mycobacterial pathogens, Mycobacterium tuberculosis (Mtb) and M. leprae. Although derived from the same mycobacterial ancestor (1), the target organs affected by these highly related mycobacteria (skin and nerves in leprosy; lungs and extrapulmonary lesions in TB) and the resulting 
clinical symptoms, are strikingly different. Notwithstanding these differences, the two poverty-associated diseases also share important characteristics (2-4), including the important role of host cellular immunity in protection. In addition, both diseases display a wide spectrum of (immuno)-pathological features with characteristic granulomatous lesions that often result in chronic disease and require prolonged treatment with multidrug antibiotic therapies (5).

Although rarely lethal, leprosy is enormously feared for causing lifelong handicaps and deformities resulting from irreversible nerve damage. Leprosy is notable for its continued transmission, which results in a stable annual number of approximately 200,000 new cases (6). Moreover, predictions from mathematical modeling indicate that millions linger undetected (7).

Tuberculosis is a major threat due to its high morbidity and mortality, causing an estimated 10.4 million new cases and 1.8 million deaths in 2015 alone (8). This scenario is worsened by HIV co-infection as well as by the emergence of multi-, extensive-, and total-drug resistance (8). Though not as threatening as for $\mathrm{TB}$, anti-microbial resistance also poses a risk for leprosy (9-13), which needs to be considered in post-exposure prophylactic (PEP) treatment strategies in leprosy endemic areas that aim to reduce transmission by administering a single dose of antibiotics to those at high risk of developing leprosy (14).

In order to combat both diseases, global strategies have been endorsed, promoting the implementation of new drugs to shorten lengthy chemotherapeutic regimens, including strategies to avoid occurrence of de novo antibiotic resistance (15). In addition, research is focusing on development of improved diagnostics for detection of infection and early stages of disease allowing prophylactic and timely treatment, respectively. In contrast to chemoprophylaxis, vaccines would be expected to give rise to active as well as long-term protection. Therefore, development of novel vaccines is an additional top priority to control TB and leprosy by preventing disease and transmission $(6,16,17)$. To explore this further, we here review the current vaccine development pipelines for $\mathrm{TB}$ and leprosy focusing on shared features and antigenic components, as well as highlight potential differences and incompatibilities.

\section{BACILLE CALMETTE-GUÉRIN (BCG), ONE VACCINE FITS ALL?}

Mycobacterium bovis, BCG still is the only vaccine used against TB worldwide $(18,19)$. It is the first live-attenuated bacterial vaccine administered to newborns at or shortly after birth and has been applied in 172 countries $(20,21)$. In spite of its efficacy against severe TB in children, protection against TB in adolescents and adults is not sufficient to impact on disease and transmission. This urges for new, more efficient vaccines, and alternative strategies to replace or complement BCG (22-24).

Although being introduced and licensed for prevention of TB, BCG was soon recognized to protect partly also from leprosy (25-27). The efficacy of BCG vaccination against TB and leprosy has been evaluated in numerous clinical trials and observational studies. However, these studies also revealed inconsistent and sometimes even contradictory results. BCG's protective effects varied from 2 to $83 \%$ and from 58 to $74 \%$ in preventing pulmonary and extrapulmonary $\mathrm{TB}$, respectively (28), while its efficacy against leprosy ranged from 26 to $41 \%$ in experimental studies to $61 \%$ in observational studies, with mild differences between the paucibacillary (62\%) and multibacillary (76\%) forms $(25,29-31)$. BCG vaccination does not seem to protect against the third most common mycobacterial disease, Buruli ulcer's disease, although a definite conclusion requires further well-designed prospective studies (32). Apart from its effect on mycobacterial diseases, BCG vaccination has been reported to have significant impact on unrelated diseases, probably through training of the innate immune system to respond more favorably to outer assaults $(33,34)$.

The remarkable differences in efficacy in various trials for TB and leprosy have been ascribed to several factors, including diversity in the genetic fingerprints of the mycobacterial pathogens in different geographic areas $(35,36)$, the various BCG strains used in the studies $(37,38)$, the immune, nutritional, and socioeconomic status of the vaccinees enrolled (39), the presence of helminths or viral coinfections $(21,40,41)$, the background exposure to and induction of immunity by environmental mycobacteria, which might mask or block the effects of BCG (42), but the precise reasons for this remain largely unclear.

Our incomplete understanding of which components of the human immune system are responsible for either successful or inefficacious protection following BCG vaccination impedes the rational design of more effective vaccines (43). For instance, the limited efficacy of BCG in preventing local pulmonary TB disease compared to its effects on disseminated forms of TB is well documented, but remains unexplained (19). One hypothesis attributes this finding to its inability to induce durable and effective immune cells that home to the lung (19). Therefore, new routes of BCG administration, such as aerosol or intranasal immunization, are tested to initiate mucosal immunity and promote homing of immune cells to the lung mucosa $(44,45)$.

Another shortcoming of BCG is that its protective effects against TB as well as leprosy wanes over time, dropping to $14 \%$ efficacy after 10-20 years (46), indicating a suboptimal induction of long-term immune memory responses as discussed above $(47,48)$. Thus, BCG revaccination has been attempted in several countries. As a first attempt, a large trial in Malawi showed that BCG revaccination had limited impact on $\mathrm{TB}$, while reducing the risk of leprosy with $50 \%(25,49)$. Similarly, a large randomized controlled TB trial in Brazil showed that a second dose of BCG in adolescents did not confer better protection than a single dose given at birth (50). In contrast, for leprosy (30, 31), BCG revaccination is officially recommended in Brazil, since the 1970s for household contacts of leprosy patients as a boost to routine neonatal BCG vaccination. More recently, an extensive BCG revaccination trial of household contacts of leprosy patients in Brazil showed that the protection conferred by a booster BCG vaccination was $56 \%$ and was independent of previous BCG vaccination (29).

Notwithstanding, this lack of BCG boosting effects in TB and its beneficial effects on leprosy, BCG vaccination can also have less 
favorable effects, such as increasing the numbers of paucibacillary leprosy cases within the first months after BCG immunization (51). This is thought to be due to excessive boosting of pre-existing M. leprae-specific T cells in those already frequently exposed to the bacterium $(51,52)$, or to hyperinflammatory innate immunity $(53,54)$. Both mechanisms could lead to pathogenic immunity, such as increased numbers of paucibacillary leprosy and leprosy reactions (55).

Based on the premise that BCG might overcome the phenotypic cellular immunological tolerance against $M$. leprae in multibacillary leprosy, BCG immunotherapy has been trialed in leprosy patients in Venezuela in the 1980s (56). These studies met with limited success, since complications of this therapy were the occasional occurrence of disseminated cutaneous BCG lesions and the induction of leprosy reactional episodes (57). In contrast, a small-sized clinical trial in India studied a combination of MDT and immunotherapy with BCG in newly diagnosed leprosy patients and found a significant reduction in duration of reactions, incidence of type 2 reactions as well as in time to achieve bacterial clearance (58).

In summary, BCG has significant protective efficacy against severe TB in children and against leprosy in adults, while BCG revaccination has added value in leprosy, but not in TB. Future changes in TB vaccination policies might, therefore, also affect leprosy control. To further analyze this issue, we review current vaccine development pipelines and policies for $\mathrm{TB}$ and leprosy, focusing on shared target product profiles and antigenic composition.

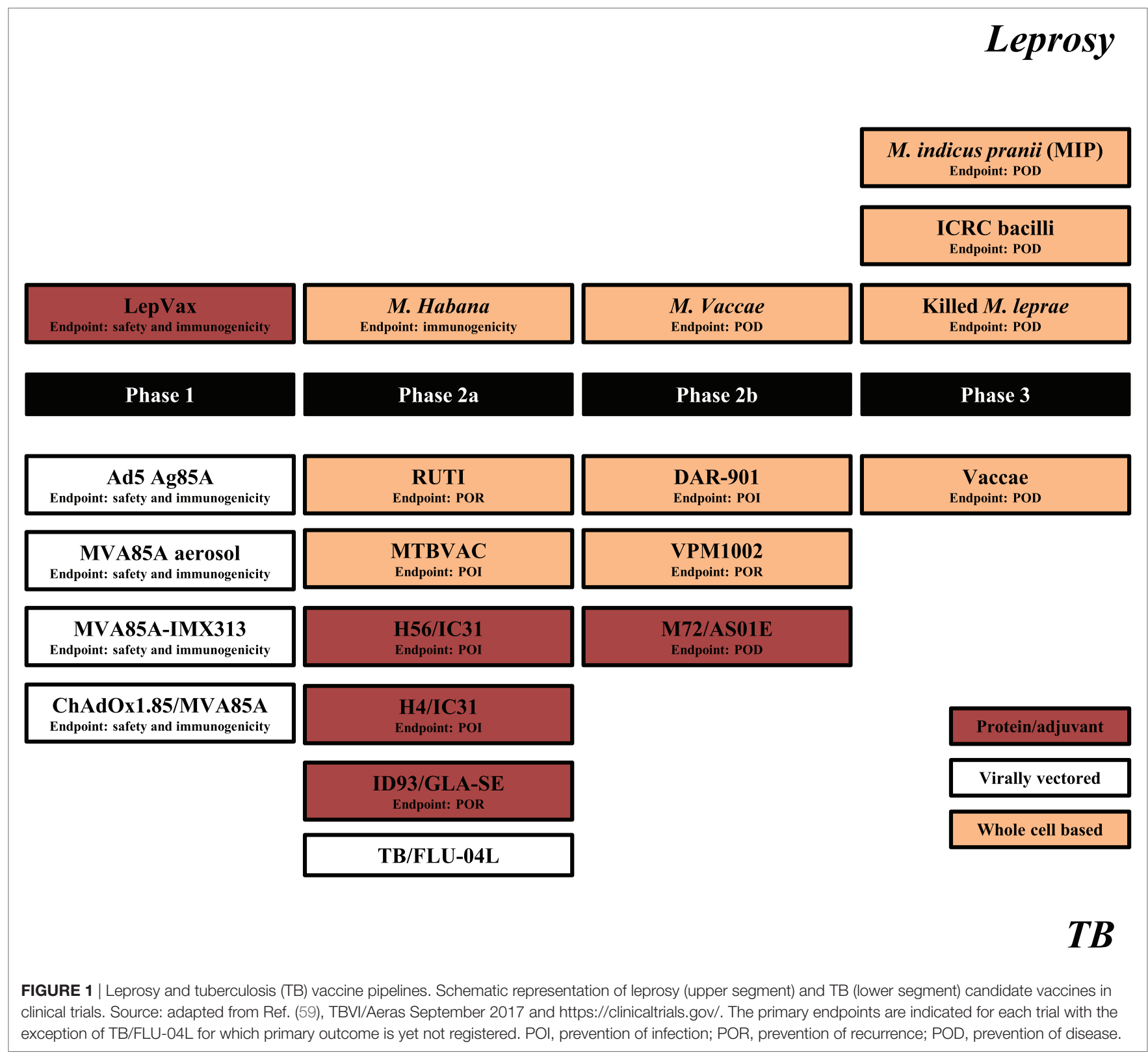




\section{VACCINES IN CLINICAL TRIALS: AT THE CROSSROAD BETWEEN LEPROSY AND TB}

Although BCG vaccination trials in leprosy were executed decades ago, the current leprosy clinical vaccine pipeline is three times smaller than that of TB (Figure 1). This situation is relatively recent considering that in 2001 there were four candidate leprosy vaccines (being) tested in clinical trials vs. none against TB.

\section{Vaccine Candidates}

The leprosy vaccine pipeline employs both live $(26,60)$ and killed $(26,56,61-63)$ whole cell mycobacterial vaccines as well as adjuvanted recombinant protein vaccines, such as LepVax (64), which have the advantage over BCG and other replicating live vaccines that they can be used safely also in immunocompromised individuals (65). LepVax comprises a hybrid recombinant protein, linking four M. leprae antigens: ML2531, ML2380, ML2055, and ML2028 (LEP-F1) (Table 1), formulated in a stable emulsion with a synthetic, TLR4 agonist (GLA-SE) as adjuvant which has recently finished pre-clinical testing (66). In line with the extent of the epidemic, the TB vaccine pipeline is much larger. This includes candidates using various delivery platforms, such as virally vectored vaccines (67-70), adjuvanted subunits vaccines (71-74), recombinant BCGs (75), genetically attenuated $M t b s$, as well as heat killed whole mycobacterial cell-based vaccines (76-79) (Figure 1). Evidently, the TB subunit vaccine pipeline has focused on a limited number of candidate $M t b$ antigens, in particular: Ag85A, Ag85B, early secretory antigenic target (ESAT6), TB10.4, Rv1813, Rv2608, Rv3619-3620, Rv1196, and Rv0125 (Table 1).

\section{Clinical Endpoints}

Leprosy and TB vaccines have different target product profiles and clinical endpoints to be considered in efficacy trials, e.g., prevention of infection (POI), prevention of disease (POD), or prevention of recurrence (POR) (80). POD require extensive longitudinal studies due to the long incubation times (years) in TB and leprosy (years-decades), and the limited incidence rates in most populations studied. For these reasons, alternative clinical trial designs have been developed using alternative biologically relevant endpoints, such as prevention of recurrence (POR) in cured TB patients, which evaluate whether relapse rates can be reduced by post-therapy vaccination; or shortening of treatment trials, which evaluate whether treatment length can be reduced by complementary immunotherapy with $\mathrm{TB}$ vaccines during the last phase of TB treatment. For leprosy, vaccines could be positioned to help preventing nerve damage in patients, since this clinical endpoint has a much higher frequency in leprosy patients, requires a shorter follow-up period and is a highly relevant endpoint in leprosy. New clinical trial designs with alternative endpoints will be important to accelerate the clinical evaluation of new vaccines for TB and leprosy, and signals detected in such studies can be validated in larger studies against classical endpoints, such as POD and perhaps POI.

\section{Clinical Trials}

In most vaccination trials for leprosy, the protective effects of the tested new vaccine candidates were equivalent to that of BCG (81). Only in one study, vaccination with Indian Cancer Research Centre bacilli (an M. leprae-related cultivable mycobacterium) and BCG plus killed $M$. leprae showed a twofold increased protection against leprosy compared to BCG alone (26). However,

TABLE 1 | Homology between tuberculosis (TB) vaccine components and Mycobacterium leprae proteins.

\begin{tabular}{|c|c|c|c|c|c|c|c|c|}
\hline \multicolumn{2}{|c|}{$\begin{array}{l}\text { Mycobacterium tuberculosis } \\
\text { proteins }\end{array}$} & \multicolumn{2}{|c|}{ Identity } & \multicolumn{2}{|c|}{ Homology } & \multirow[t]{2}{*}{ M. leprae orthologs } & \multirow[t]{2}{*}{ Vaccine candidate } & \multirow[t]{2}{*}{ References } \\
\hline Rv number & Gene name & $\begin{array}{l}\text { Amino acid } \\
\text { (aa) overlaps }\end{array}$ & $\%$ & aa overlaps & $\%$ & & & \\
\hline Rv3804c & $\begin{array}{l}\text { Antigen 85A } \\
\text { (Ag85A) }\end{array}$ & 273/329 & $83 \%$ & 296/329 & $90 \%$ & ML0097 & $\begin{array}{l}\text { Ad5 Ag85A; MVA85A aerosol; } \\
\text { MVA85A-IMX313; ChAdOx1. } \\
\text { 85/MVA85A; TB/FLU-04L }\end{array}$ & $(64-67)$ \\
\hline Rv1886c & Ag85B & $269 / 324$ & $84 \%$ & $288 / 324$ & $89 \%$ & ML2028 & $\begin{array}{l}\text { H56/IC31; H4/IC31; } \\
\text { TB/FLU-04L; LepVax }\end{array}$ & (61) \\
\hline Rv3875 & $\begin{array}{l}\text { Early secretory } \\
\text { antigenic target }\end{array}$ & $35 / 91$ & $39 \%$ & $61 / 91$ & $68 \%$ & ML0049 & H56/IC31 & (68) \\
\hline Rv2660 & Rv2660 & & & & & & H56/IC31 & (68) \\
\hline Rv0288 & TB10.4 & $68 / 96$ & $71 \%$ & $82 / 96$ & $86 \%$ & ML2531 & H4/IC31; LepVax & $(61,69)$ \\
\hline Rv1813c & Rv1813c & nssf & nssf & nssf & nssf & & ID93/GLA-SE & $(70)$ \\
\hline Rv2608 & PPE42 & $65 / 156$ & $42 \%$ & $88 / 156$ & $56 \%$ & PPE familya & ID93/GLA-SE & $(70)$ \\
\hline Rv3619c & EsxV & $59 / 92$ & $64 \%$ & 74/92 & $80 \%$ & ML1056 & ID93/GLA-SE & $(70)$ \\
\hline Rv3620c & EsxW & $55 / 95$ & $58 \%$ & $73 / 95$ & $76 \%$ & ML1055 & ID93/GLA-SE & $(70)$ \\
\hline Rv1196 & PPE18 & $173 / 419$ & $41 \%$ & $228 / 419$ & $54 \%$ & ML1054 & M72/AS01E & $(71)$ \\
\hline Rv0125 & PepA & $250 / 358$ & $70 \%$ & $292 / 358$ & $82 \%$ & ML2659 & M72/AS01E & $(71)$ \\
\hline Rv1860 & Apa & $197 / 298$ & $67 \%$ & $218 / 298$ & $74 \%$ & ML2055 & LepVax & $(61)$ \\
\hline Rv0455c & Rv0455c & $101 / 152$ & $67 \%$ & $113 / 152$ & $75 \%$ & ML2380 & LepVax & $(61)$ \\
\hline
\end{tabular}

${ }^{a}$ Accession number not known; nnsf, no significant similarity found.

${ }^{b}$ Pseudogene. 
M. indicus pranii (MIP) (also known as Mycobacterium w.) induced protective efficacy below that of BCG. Notwithstanding this result, MIP was evaluated also in a second, large-scale, double-blind trial with a 9-year follow-up (62). In this study, the protective efficacy of MIP in vaccinated household contacts after 3 years was the highest ever reported against leprosy (68\%) for a vaccine other than BCG. However, its protective effect dropped considerably after $6(60 \%)$ and 9 (28\%) years of follow-up. Despite these conflicting results, MIP is currently being evaluated both as prophylactic and therapeutic vaccine against leprosy in two high endemic districts in India (82) in combination with a single dose of rifampicin (SDR). This design is reminiscent of a previous randomized vaccine field trial in which BCG as well as SDR was provided to leprosy contacts (83).

For TB, several vaccines and vaccine approaches are being pursued, with no new TB vaccine approved, yet for use, since the introduction of BCG in 1921. The results from the recent MVA85A vaccine phase $2 \mathrm{~b}$ efficacy trial, the first new TB vaccine tested in an efficacy trial, since BCG, showed no improved protection in BCG-vaccinated South African infants (84), despite being highly immunogenic in adults (85). Several trials are ongoing (Figure 1), with the first outcomes to become available in 2018.

\section{Correlates of Protection}

Vaccine immunogenicity studies for both leprosy and TB vaccine candidates have mostly focused on their ability to induce type-1 cell-mediated immunity, particularly CD4+ Th cells releasing type 1 helper (Th1) cytokines. Indeed, Th1 immunity is widely considered to be key in controlling mycobacterial infections (86). HIV-induced CD4+ T cell deficiency, and genetic or acquired impairments in type 1 cytokine signaling (IL12-IFN- $\gamma$ axis), all increase susceptibility to mycobacterial infection and progressive disease in humans and animal models (87-90). In leprosy, the presence of Th1 cytokines in lesions or in lepromin skin reactions has been related to better clinical prognosis and to localized rather than disseminating disease $(91,92)$. Furthermore, individuals that showed large local reactogenicity after intradermal BCG administration or lepromin injection are reported to have less risk for leprosy onset (93). Observation from a small Dutch cohort of BCG-vaccinated individuals showed that high skin inflammation responders had a larger amount of C-reactive protein in their sera than the low skin inflammation responders. In the same study, at 4,8 , and 12 weeks post-BCG vaccination, PBMCs of individuals with stronger local reactogenicity induced higher IFN- $\gamma$ production

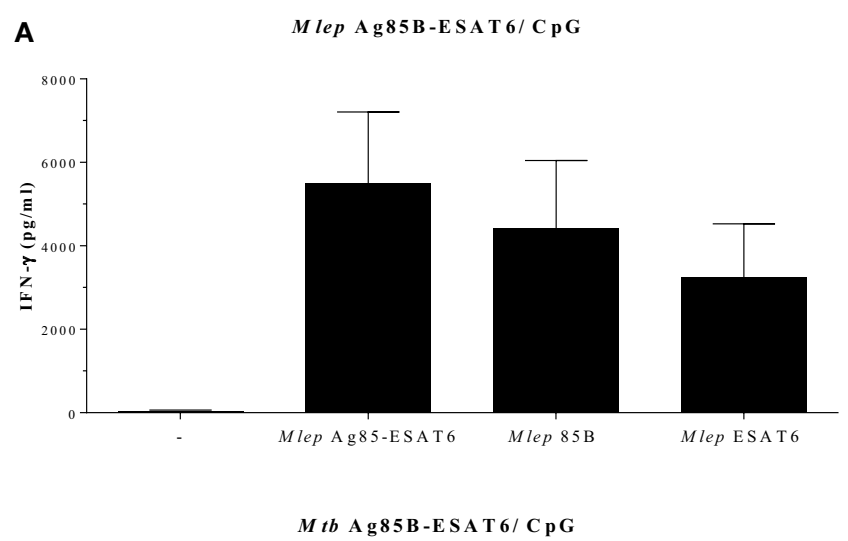

B

M lep Ag85B-ESAT6/ GLA-SE

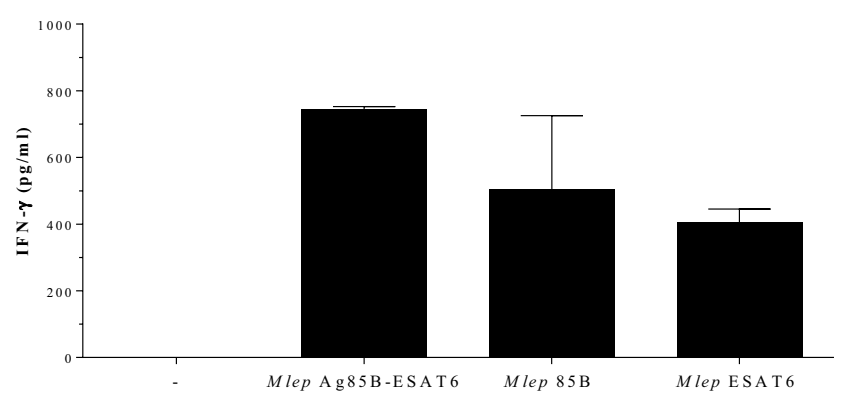

Mtb Ag85B-ESAT 6/ GLA-SE
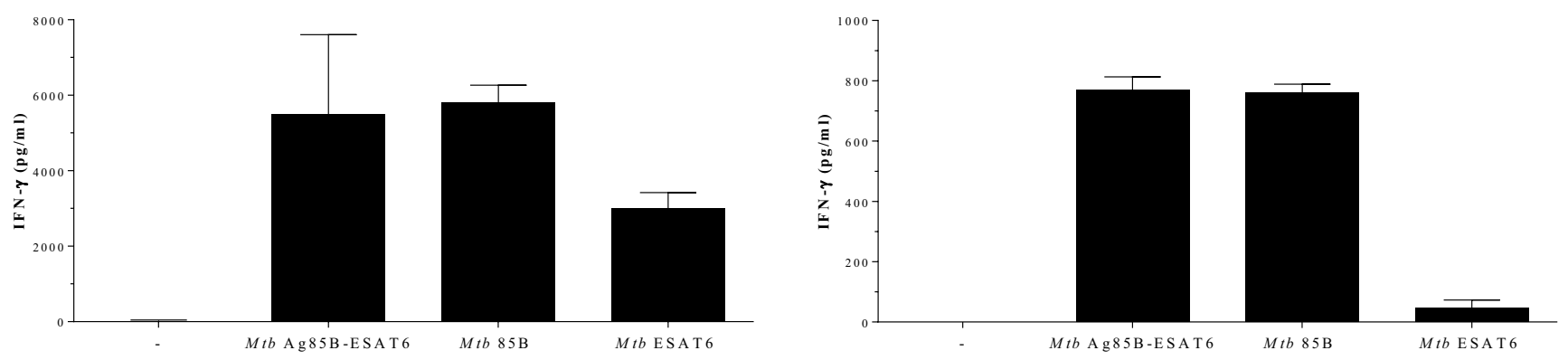

FIGURE 2 | IFN- $\gamma$ secretion after Ag85-ESAT immunization. C57BL/6j and HLA-A2tg mice B6.Cg-Tg (117) were purchased from The Jackson Laboratory (Bar Harbor, ME, USA) and housed under specific pathogen-free conditions. Recombinant proteins were overexpressed in E. coli BL21 (DE3) and purified to remove any traces of endotoxin as described in Ref. (116, 118). For the production of the antigen 85B (Ag85B)-early secretory antigenic target (ESAT6), hybrid recombinant hybrid protein, the Ag85B and ESAT6 genes were fused together by PCR with a linker coding for the amino acids NVA. C57BL/6j mice [(A); 13-14 animals per group] and HLA-A2tg mice [(B); 5 animals per group] were immunized three times subcutaneously with Mycobacterium tuberculosis (Mtb) Ag85-ESAT or Mycobacterium leprae Ag85-ESAT recombinant protein $(25 \mu \mathrm{g})$ adjuvanted with GLA-SE [glucopyranosyl lipid adjuvant-stable emulsion (23) kindly provided by Infectious Disease Research Institute; Seattle, WA, USA; TLR4 agonist; 20 mg]; or CpG (ODN1826 5'-TCC ATG ACG TTC CTG ACG TT -3'; InvivoGen, San Diego, CA, USA; TLR9 agonist; $50 \mu \mathrm{g}$ ) (119). Splenocytes were harvested 4 weeks after final injections and restimulated in vitro with Mtb or M. leprae Ag85-ESAT hybrid recombinant proteins or the single Ag85B and ESAT6 recombinant proteins (all $10 \mu \mathrm{g} / \mathrm{ml})$. IFN- $\gamma$ secretion was analyzed by ELISA after 5 days. All mice were analyzed separately. Data shown indicate the mean and SE value of five mice per group. 
after in vitro PPD stimulation than the one from the group with less local reaction to BCG (94). This suggests that skin reactogenicity after BCG vaccination causing local inflammation and systemic Th1 responses probably indicate protective immunity to mycobacteria. The failure of MVA85A against TB despite its induction of CD4+ Th1 immunity, the observation that BCGspecific CD4+ and CD8+ T-cell responses did not correlate with protection against TB disease in one study (95) together with the limited results achieved by current leprosy vaccines, clearly underline the need for a better understanding of the host mechanisms that are responsible for protection against both
TB and leprosy. Several recent reports in animal models and humans have reported the involvement of other cell subsets in leprosy and TB $(96,97)$. Discovering these mechanisms may well prove to be a critical step for designing more effective vaccines.

Besides BCG, only MIP and killed M. vaccae have been clinically evaluated for both leprosy and TB, although in different trial designs and target populations. MIP has been tested for its putative therapeutic efficacy in tuberculous pericarditis (98) and as mentioned above for its protective efficacy against leprosy $(26,62)$. Killed M. vaccae has been assessed for its ability to prevent $\mathrm{TB}$ and leprosy disease in patients or contacts.
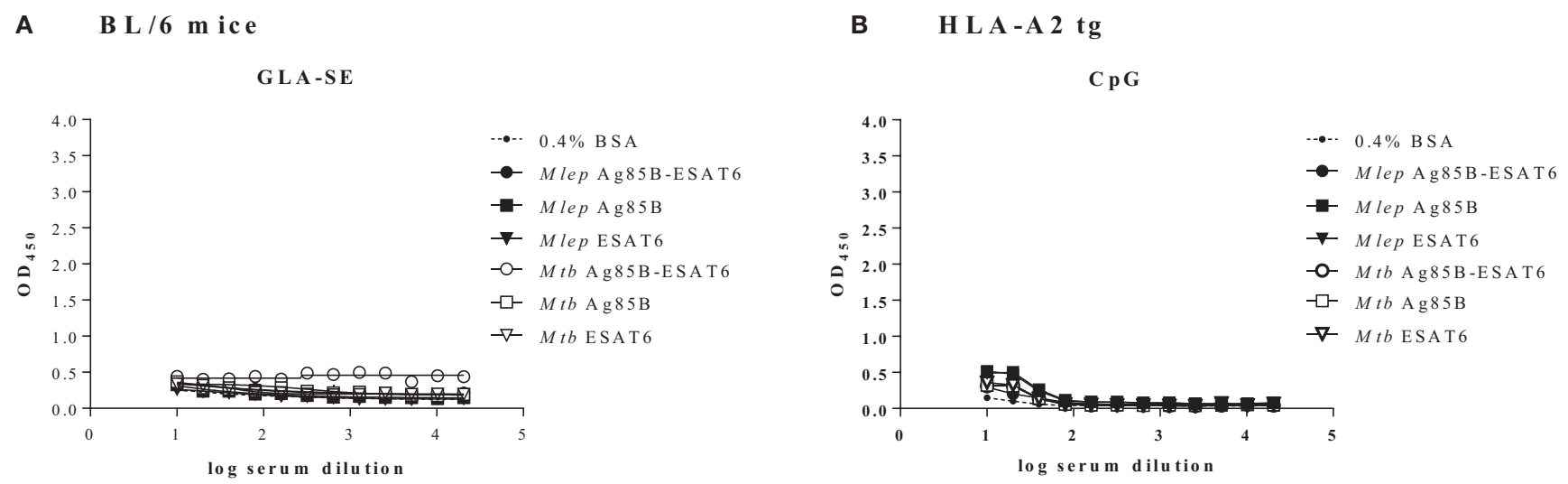

M tb A g85B-E S A T 6/G L A -S E

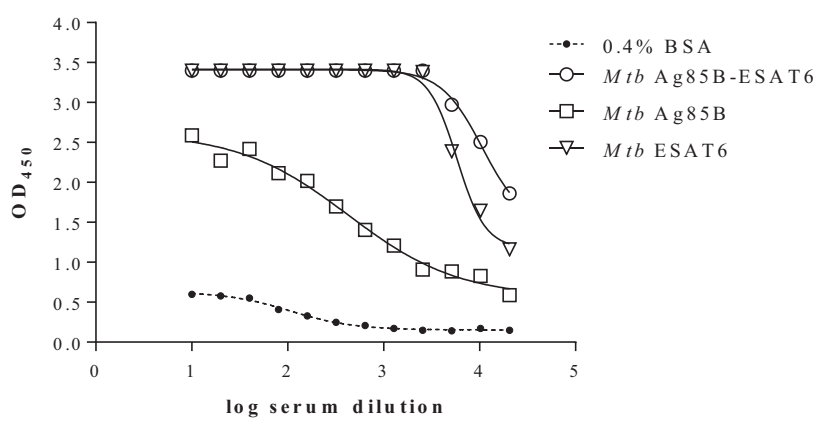

M lep Ag85B-ESAT 6/ G L A-S E

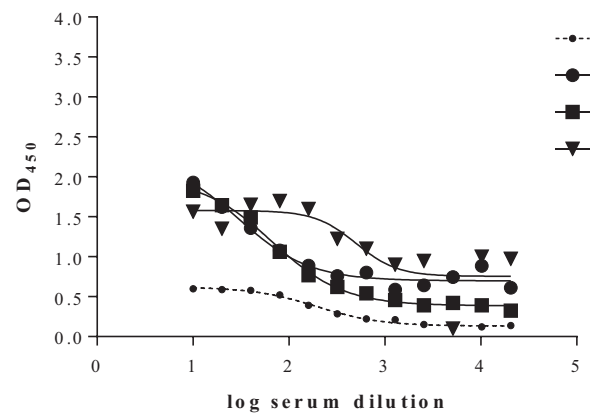

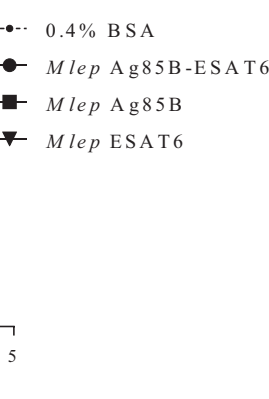

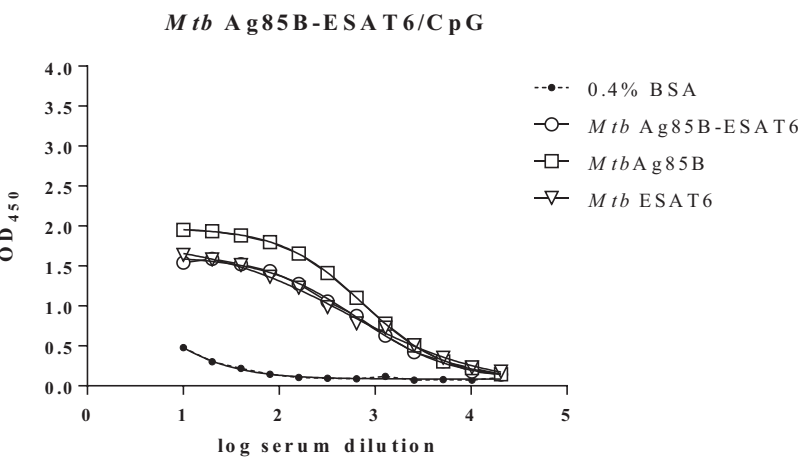

M lep A g85B-E SA T 6/C p G

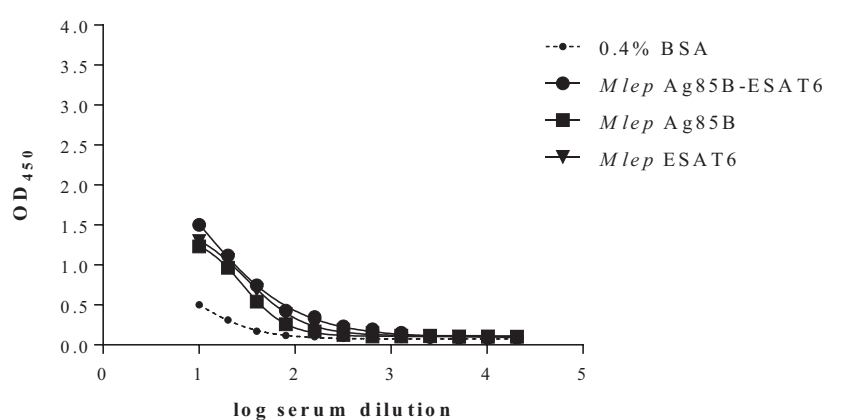

FIGURE 3 | Quantification of serum antibodies. Following immunization of C57BL/6j (A) and HLA-A2 tg (B) mice with adjuvant alone, Mycobacterium tuberculosis

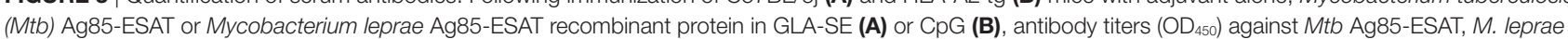
Ag85-ESAT, or Mtb/M. leprae Antigen 85B (Ag85B) and early secretory antigenic target (ESAT6) were determined by ELISA as described in Ref. (120). As a control coating with BSA $(0.4 \%$ in PBS) was used. Sera from immunized mice were collected from cardiac blood 3 weeks after final immunization Serum dilutions are shown on the $x$-axis. Test groups included 3-5 mice. All mice were analyzed separately. Results are shown for one representative animal. 
However, the administration routes (intramuscular vs. oral vs. intradermal injection of $M$. vaccae) and the eligibility criteria for the recruitment in the two trials (inclusion or not of individuals with BCG scar; HIV-positivity; anti-mycobacterial therapy) were quite diverse, impeding direct comparison of the impact of $M$. vaccae vaccination on both diseases $(63,78)$.

\section{ONE SUBUNIT VACCINE FOR BOTH TB AND LEPROSY?}

With the exception of $M$. habana $(60,99)$, the majority of vaccines evaluated for both leprosy and TB were initially designed as TB vaccines, and only evaluated at a later stage for their potential in leprosy. Since $M$. leprae has undergone massive gene reduction (100), not all $M t b$ antigens that are potential targets for $\mathrm{TB}$ vaccines have corresponding homologs in M. leprae. The first examples are ID83/GLA-SE and ID93/ GLA-SE, two recombinant fusion proteins, formulated with the TLR4L-containing adjuvant GLA-SE, and consisting of three $M t b$ proteins: Rv1813, Rv2608, and Rv3620, with the further addition of Rv3619 in ID93. The amino acid (aa) sequences of Rv3619 and Rv3620 are 58 and 64\% identical to the respective $M$. leprae proteins (ML1056 and ML1055, respectively) (Table 1). Likely due to these similarities, both $M t b$ hybrid recombinant proteins were also recognized by blood from paucibacillary leprosy patients, although latent $M t b$ infection could have explained these findings as well. Furthermore, when injected subcutaneously these vaccines reduced $M$. lepraeinduced inflammation and bacterial growth in mouse models of leprosy (65), suggesting that TB subunit vaccines might have efficacy also against leprosy.

In a similar approach, we have investigated another $\mathrm{TB}$ subunit vaccine candidate, consisting of two major secreted $M t b$ proteins: $M t b$ ESAT6 and Mtb Ag85B, both present in shortterm $M t b$ culture filtrates $(101,102)$. Ag85B is highly conserved among mycobacterial species, probably due to its critical role in cell wall synthesis as a mycolyltransferase (103). ESAT6 is a secreted virulence protein mainly restricted to the $M t b$ complex organisms (104). Both antigens have been extensively studied in the TB field over the past three decades and proved to be strongly recognized by CD4 Th1-cells of TB patients and latently TB infected (LTBI) individuals (105). Demonstrated to be immunodominant during $M t b$ infection, the two recombinant
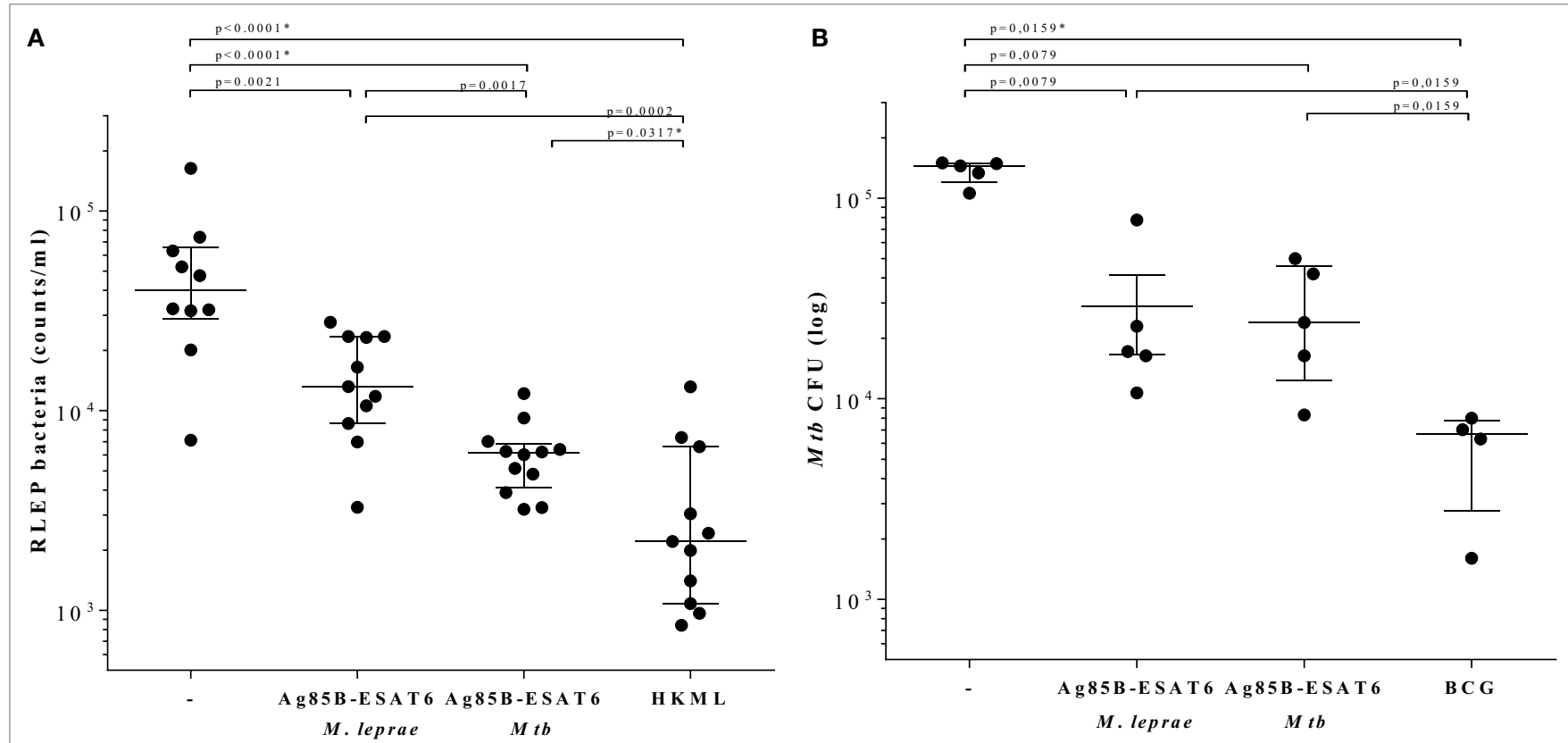

FIGURE 4 | Determination of bacterial burden. C57BL/6j mice were injected with $10^{4}$ live Mycobacterium leprae (121) (viability: 11,000; in 40 $\mu$ I PBS) in each hind foot pads 4 weeks after the final protein immunization. 7 months after $M$. leprae challenge, mouse footpads were harvested, and $M$. leprae were enumerated by RLEP PCR (122). HLA-A2tg mice were infected with live Mycobacterium tuberculosis (Mtb) strain H37Rv 6 weeks after the final protein immunization and 10 weeks after Bacille Calmette-Guérin (BCG) immunization (119). All animals included in the experiments were observed daily in order to ensure ethics requirements and to monitor any adverse effects possibly related to the vaccination or infection. (A) Bacteria were determined by the RLEP PCR from footpads from M. leprae infected C57BL/6j mice that had been immunized with GLA-SE adjuvant alone (-), M. leprae Ag85-ESAT/GLA-SE, Mtb Ag85-ESAT/GLA-SE, or heat killed M. leprae (HKML; $2 \times 10^{8}$ in $40 \mu$; viability: 6,400) as indicated on the $x$-axis. Each symbol represents one mouse. Calculated bacterial loads are expressed as RLEP counts on the $y$-axis. Horizontal lines indicate median values with interquartile range. (B) CFUs were determined in lung homogenates from $M$ tb-infected unimmunized (-) or Mtb-infected HLA-A2 tg mice that were immunized with BCG1331 (10 6 CFU), M. leprae Ag85-ESAT or Mtb Ag85-ESAT as indicated under the $x$-axis. Each symbol represents one mouse. Bacterial loads are expressed as log10 bacterial counts. Horizontal lines indicate median values with interquartile range. CFU of test and control groups were compared to the controls using the Mann-Whitney test and a $p<0.01$ was considered significant. * marks differences that remained significant after multiple test correction using Kruskal-Wallis testing with Dunn's post-test. 
proteins were fused into a recombinant hybrid protein, and adjuvanted with the Th1 inducing synthetic adjuvant IC $31^{\circledR}$. In several animal models, including mice, guinea pigs, and non-human primates, Ag85B-ESAT6/IC31 showed promising protective efficacy against TB disease $(106,107)$. Based on these results, the vaccine was progressed to human phase $1 / 2 \mathrm{a}$ trials $(105,108,109)$. This work demonstrated the vaccine's safety and its remarkable ability to induce long-lasting Th1-type immune reactivity in healthy or HIV-negative, mycobacterially naive individuals, LTBI, and BCG-vaccinated volunteers (109-111) even 3 years after the second vaccination.

In view of several characteristics, Ag85B-ESAT6 is an interesting candidate for leprosy as well. Mtb ESAT6 and Ag85B share 68 and $89 \%$ aa overlaps (homology according to pre-computed Tuberculist Blastp) with M. leprae homologs, ML0049, and ML2028, respectively (Table 1). These proteins are widely recognized by antibodies of multibacillary leprosy patients $(112,113)$, as well as by IFN- $\boldsymbol{\gamma}$ secreting cells from paucibacillary leprosy patients (64). We previously demonstrated T-cell cross-reactivity between $M t b$ and $M$. leprae ESAT6 in leprosy and TB patients (114). Moreover, a previous study showed that Ag85B overexpression in BCG significantly increased BCG's protective efficacy against $M$. leprae (115). To further explore and compare the efficacy of Ag85B-ESAT6-based vaccines against TB and leprosy, we generated both $M t b$ Ag85B-ESAT6 and M. leprae Ag85B-ESAT6 and studied their in vivo efficacy in mouse models of $M t b$ and M. leprae infection.

\section{Mtb and $M$. leprae Ag85B-ESAT6-Based Vaccines: A Comparative Evaluation}

In order to evaluate the immunogenicity of $M t b$-Ag85BESAT6 and M. leprae-Ag85B-ESAT6, both hybrid recombinant proteins were produced (116) and injected subcutaneously in wild-type C57BL/6j (BL/6) mice, as well as in C57BL/6j (BL/6) mice expressing an HLA-A ${ }^{\star} 0201$ transgene. The proteins were formulated with GLA-SE (TLR4 agonist) or CpG (TLR9 agonist), respectively, both of which have been reported to drive Th1-type responses. As expected, we detected high levels of IFN- $\gamma$ released by splenocytes from immunized mice in response to $M t b$ Ag85B-ESAT6, M. leprae Ag85B-ESAT6, and their individual components (Figure 2). Total IgG, IgA, and IgM levels against $M t b$ Ag85B-ESAT6, M. leprae Ag85BESAT6, and the individual proteins were increased as well in both mouse strains following immunizations (Figure 3). Interestingly, the highest antibody titers were observed against $M t b$ Ag85B-ESAT6, regardless of whether Mtb Ag85B-ESAT6 or M. leprae Ag85B-ESAT6 had been used to immunize BL/6 mice (Figure 3A). Most importantly, both Mtb Ag85B-ESAT6/ GLA-SE or M. leprae Ag85B-ESAT6/GLA-SE vaccines were capable of inducing host control of $M t b$ and $M$. leprae infection to a significant and comparable extent. Interestingly, $M t b$ Ag85B-ESAT6/GLA-SE controlled $M$. leprae infection significantly better than M. leprae Ag85B-ESAT6/GLA-SE (Figure 4). In summary, these results suggest that novel subunit vaccines designed for TB, such as Mtb Ag85B-ESAT6 could have efficacy against both TB and leprosy.

\section{CONCLUDING REMARKS}

Leprosy and TB are still major poverty-related health concerns. Leprosy is primarily endemic in geographic areas, where TB is also highly prevalent (115). To date, BCG has been used predominantly as a vaccine against TB, but it also contributes to the control of leprosy. However, due to its limited efficacy especially against pulmonary TB in adults, the main and contagious form of $\mathrm{TB}$, novel vaccines are being developed to replace or boost BCG (Figure 1). Although these vaccines will likely also impact leprosy incidence, this issue is rarely considered, let alone studied in extensive trials.

There are two leprosy vaccine candidates, MIP in India (82) and LepVax (66), and the TB vaccine pipeline is much more advanced and diverse than the one for leprosy. Even though it is likely that a TB vaccine candidate will emerge, for none of the current TB candidate vaccines, the impact on leprosy is currently being taken into account.

Only two highly similar recombinant subunit TB vaccines, based on the same backbone design, have been tested for their potential use against leprosy (65). Here, we describe original data showing a second TB subunit candidate vaccine platform, based on Ag85B/ESAT6. Collectively, our data suggest that novel TB vaccine candidates can cross-protect against leprosy, providing support for integrating leprosy vaccine research with $\mathrm{TB}$ vaccine research $(65,81,115)$. At the moment, the most advanced new TB vaccine candidates have been tested in India, Tanzania, China, South Africa, the first two of which have elevated incidences of leprosy. Thus far, none of these recent trials have included evaluation of impact on leprosy, unlike what was done decades ago for BCG(61). We contend that preclinical integration and harmonization of TB/leprosy discovery and development research would well be feasible with respect to the design of subunit vaccines, as we have in fact applied in our recent approach for vaccine antigen discovery (123). With respect to antigen selection algorithms, it is of interest to consider the extensive genomic reduction that $M$. leprae has undergone during evolution $(100,124)$, causing this Mycobacterium to become a highly specialized and obligate intracellular pathogen (125). Studying M. leprae's successful minimalistic approach will reveal genetic and metabolic pathways that pathogenic mycobacteria need to survive in the host, and inspire drug and vaccine efforts to combat both diseases which have put such a heavy toll on humans for millennia.

\section{ETHICS STATEMENT}

The handling of mice was conducted in accordance with the regulations set forward by the animal care committee of the LUMC and in compliance with European Community Directive 86/609 for the care and use of laboratory animals. The experiments at NHDP were performed under a scientific protocol reviewed and approved by the NHDP Institutional Animal Care and Use Committee (Assurance \#A3032-01) and were conducted in accordance with all state and federal laws in adherence with PHS policy and as outlined in The Guide for the Care and Use of Laboratory Animals, Eighth Edition. 


\section{AUTHOR CONTRIBUTIONS}

Concept of the review: AG and TO. Designed and wrote the review: MC, TO, and AG. Figures and legends: SE, KF, NR, LW, and LA. Final approval of the version to be published: all authors.

\section{ACKNOWLEDGMENTS}

We want to thank Peter Andersen (SSI, Copenhagen, Denmark) for helpful discussions at the initiation of this project and IDRI (Seattle, WA, USA) for providing GLA-SE. This study was supported by the Q. M. Gastmann-Wichers Foundation, the Netherlands Leprosy

\section{REFERENCES}

1. Gomez-Valero L, Rocha EP, Latorre A, Silva FJ. Reconstructing the ancestor of Mycobacterium leprae: the dynamics of gene loss and genome reduction. Genome Res (2007) 17(8):1178-85. doi:10.1101/gr.6360207

2. Scollard DM, Dacso MM, Abad-Venida ML. Tuberculosis and leprosy: classical granulomatous diseases in the twenty-first century. Dermatol Clin (2015) 33(3):541-62. doi:10.1016/j.det.2015.03.016

3. Petruccioli E, Scriba TJ, Petrone L, Hatherill M, Cirillo DM, Joosten SA, et al. Correlates of tuberculosis risk: predictive biomarkers for progression to active tuberculosis. Eur Respir J (2016) 48(6):1751-63. doi:10.1183/ 13993003.01012-2016

4. van Hooij A, Geluk A. Immunodiagnostics for leprosy. In: Scollard DM, Gillis TP, editors. International Textbook of Leprosy. (2016). Available from: www.internationaltextbookofleprosy.org

5. Modlin RL, Bloom BR. TB or not TB: that is no longer the question. Sci Transl Med (2013) 5(213):213sr6. doi:10.1126/scitranslmed.3007402

6. WHO - Global Leprosy Programme. Global Leprosy Strategy 2016-2020: Accelerating Towards a Leprosy-Free World 2016. WHO (2016).

7. Smith WC, van BW, Gillis T, Saunderson P, Richardus JH. The missing millions: a threat to the elimination of leprosy. PLoS Negl Trop Dis (2015) 9(4):e0003658. doi:10.1371/journal.pntd.0003658

8. WHO. Global Tuberculosis Report 2016. WHO (2016).

9. Lavania M, Jadhav RS, Chaitanya VS, Turankar R, Selvasekhar A, Das L, et al. Drug resistance patterns in Mycobacterium leprae isolates from relapsed leprosy patients attending The Leprosy Mission (TLM) Hospitals in India. Lepr Rev (2014) 85(3):177-85.

10. Liu D, Zhang Q, Sun Y, Wang C, Zhang Y, Fu X, et al. Drug resistance in Mycobacterium leprae from patients with leprosy in China. Clin Exp Dermatol (2015) 40(8):908-11. doi:10.1111/ced.12665

11. Beltran-Alzate C, Lopez Diaz F, Romero-Montoya M, Sakamuri R, Li W, Kimura M, et al. Leprosy Drug Resistance Surveillance in Colombia: the experience of a Sentinel country. PLoS Negl Trop Dis (2016) 10(10):e0005041. doi:10.1371/journal.pntd.0005041

12. Moraes MO. Editorial commentary: drug-resistance in leprosy: moving toward understanding the scope of the problem and how to tackle it. Clin Infect Dis (2016) 63(11):1485-6. doi:10.1093/cid/ciw574

13. Dheda K, Gumbo T, Maartens G, Dooley KE, McNerney R, Murray M, et al. The epidemiology, pathogenesis, transmission, diagnosis, and management of multidrug-resistant, extensively drug-resistant, and incurable tuberculosis. Lancet Respir Med (2017) 5(4):291-360. doi:10.1016/S2213-2600(17)30079-6

14. Barth-Jaeggi T, Steinmann P, Mieras L, van Brakel W, Richardus JH, Tiwari A, et al. Leprosy Post-Exposure Prophylaxis (LPEP) programme: study protocol for evaluating the feasibility and impact on case detection rates of contact tracing and single dose rifampicin. BMJ Open (2016) 6(11):e013633. doi:10.1136/bmjopen-2016-013633

15. Kuijl C, Savage ND, Marsman M, Tuin AW, Janssen L, Egan DA, et al. Intracellular bacterial growth is controlled by a kinase network around $\mathrm{PKB} /$ AKT1. Nature (2007) 450(7170):725-30. doi:10.1038/nature06345

16. WHO. Implementing the End TB Strategy: The Essentials. WHO (2016).
Relief Foundation (ILEP\#: 702.02.65), the Order of Malta-Grantsfor-Leprosy-Research (MALTALEP), the American Leprosy Mission, Heiser Program for Research in Leprosy in The New York Community Trust P13-000392, Top Institute Pharma (project D-101-1), ISA Pharmaceuticals, the European Commission [FP7 NEWTBVAC project contract no. LSHP-CT-2003-503367, EC ITN FP7 VACTRAIN project; EC HORIZON2020 TBVAC2020 (Grant Agreement No. 643381)]. The text represents the authors' views and does not necessarily represent a position of the Commission who will not be liable for the use made of such information. Intramural support from the National Hansen's Disease programs was provided for animal studies.

17. Blok DJ, de Vlas SJ, Fischer EA, Richardus JH. Mathematical modelling of leprosy and its control. Adv Parasitol (2015) 87:33-51. doi:10.1016/ bs.apar.2014.12.002

18. Kaufmann SH, Gulle H, Daugelat S, Schoel B. Tuberculosis and leprosy: attempts to identify T-cell antigens of potential value for vaccine design. Scand J Immunol Suppl (1992) 11:85-90. doi:10.1111/j.1365-3083.1992. tb01626.x

19. Moliva JI, Turner J, Torrelles JB. Immune responses to Bacillus CalmetteGuerin vaccination: why do they fail to protect against Mycobacterium tuberculosis? Front Immunol (2017) 8:407. doi:10.3389/fimmu.2017. 00407

20. Zwerling A, Behr MA, Verma A, Brewer TF, Menzies D, Pai M. The BCG World Atlas: a database of global BCG vaccination policies and practices. PLoS Med (2011) 8(3):e1001012. doi:10.1371/journal.pmed.1001012

21. Moliva JI, Turner J, Torrelles JB. Prospects in Mycobacterium bovis Bacille Calmette et Guerin (BCG) vaccine diversity and delivery: why does BCG fail to protect against tuberculosis? Vaccine (2015) 33(39):5035-41. doi:10.1016/j.vaccine.2015.08.033

22. Cardona PJ. What we have learned and what we have missed in tuberculosis pathophysiology for a new vaccine design: searching for the "Pink Swan". Front Immunol (2017) 8:556. doi:10.3389/fimmu.2017.00556

23. Sadagopal S, Braunstein M, Hager CC, Wei J, Daniel AK, Bochan MR, et al. Reducing the activity and secretion of microbial antioxidants enhances the immunogenicity of BCG. PLoS One (2009) 4(5):e5531. doi:10.1371/ journal.pone.0005531

24. Guerrero GG, Rangel-Moreno J, Islas-Trujillo S, Rojas-Espinosa O. Successive intramuscular boosting with IFN-alpha protects Mycobacterium bovis BCG-vaccinated mice against $M$. lepraemurium infection. Biomed Res Int (2015) 2015:414027. doi:10.1155/2015/414027

25. Fine PE. Variation in protection by BCG: implications of and for heterologous immunity. Lancet (1995) 346(8986):1339-45. doi:10.1016/S0140-6736 (95) $92348-9$

26. Gupte MD, Vallishayee RS, Anantharaman DS, Nagaraju B, Sreevatsa, Balasubramanyam S, et al. Comparative leprosy vaccine trial in south India. Indian J Lepr (1998) 70(4):369-88.

27. Goulart IM, Bernardes Souza DO, Marques CR, Pimenta VL, Goncalves MA, Goulart LR. Risk and protective factors for leprosy development determined by epidemiological surveillance of household contacts. Clin Vaccine Immunol (2008) 15(1):101-5. doi:10.1128/CVI.00372-07

28. Mangtani P, Abubakar I, Ariti C, Beynon R, Pimpin L, Fine PE, et al. Protection by BCG vaccine against tuberculosis: a systematic review of randomized controlled trials. Clin Infect Dis (2014) 58(4):470-80. doi:10.1093/ $\mathrm{cid} / \mathrm{cit} 790$

29. Duppre NC, Camacho LA, da Cunha SS, Struchiner CJ, Sales AM, Nery JA, et al. Effectiveness of BCG vaccination among leprosy contacts: a cohort study. Trans R Soc Trop Med Hyg (2008) 102(7):631-8. doi:10.1016/j. trstmh.2008.04.015

30. Merle CS, Cunha SS, Rodrigues LC. BCG vaccination and leprosy protection: review of current evidence and status of BCG in leprosy control Expert Rev Vaccines (2010) 9(2):209-22. doi:10.1586/erv.09.161 
31. Setia MS, Steinmaus C, Ho CS, Rutherford GW. The role of BCG in prevention of leprosy: a meta-analysis. Lancet Infect Dis (2006) 6(3):162-70. doi:10.1016/S1473-3099(06)70412-1

32. Phillips RO, Phanzu DM, Beissner M, Badziklou K, Luzolo EK, Sarfo FS, et al. Effectiveness of routine BCG vaccination on buruli ulcer disease: a case-control study in the Democratic Republic of Congo, Ghana and Togo. PLoS Negl Trop Dis (2015) 9(1):e3457. doi:10.1371/journal.pntd. 0003457

33. Blok BA, Arts RJ, van Crevel R, Benn CS, Netea MG. Trained innate immunity as underlying mechanism for the long-term, nonspecific effects of vaccines. J Leukoc Biol (2015) 98(3):347-56. doi:10.1189/jlb.5RI0315-096R

34. Sanli O, Dobruch J, Knowles MA, Burger M, Alemozaffar M, Nielsen ME, et al. Bladder cancer. Nat Rev Dis Primers (2017) 3:17022. doi:10.1038/ nrdp.2017.22

35. Comas I, Coscolla M, Luo T, Borrell S, Holt KE, Kato-Maeda M, et al. Out-of-Africa migration and neolithic coexpansion of Mycobacterium tuberculosis with modern humans. Nat Genet (2013) 45(10):1176-82. doi:10.1038/ng.2744

36. Lavania M, Jadhav R, Turankar RP, Singh I, Nigam A, Sengupta U. Genotyping of Mycobacterium leprae strains from a region of high endemic leprosy prevalence in India. Infect Genet Evol (2015) 36:256-61. doi:10.1016/j. meegid.2015.10.001

37. Abebe F, Bjune G. The emergence of Beijing family genotypes of Mycobacterium tuberculosis and low-level protection by bacille CalmetteGuerin (BCG) vaccines: is there a link? Clin Exp Immunol (2006) 145(3): 389-97. doi:10.1111/j.1365-2249.2006.03162.x

38. Brosch R, Gordon SV, Garnier T, Eiglmeier K, Frigui W, Valenti P, et al. Genome plasticity of BCG and impact on vaccine efficacy. Proc Natl Acad Sci U S A (2007) 104(13):5596-601. doi:10.1073/pnas.0700869104

39. Hoang T, Agger EM, Cassidy JP, Christensen JP, Andersen P. Protein energy malnutrition during vaccination has limited influence on vaccine efficacy but abolishes immunity if administered during Mycobacterium tuberculosis infection. Infect Immun (2015) 83(5):2118-26. doi:10.1128/ IAI.03030-14

40. Hagge DA, Parajuli P, Kunwar CB, Rana D, Thapa R, Neupane KD, et al. Opening a can of worms: leprosy reactions and complicit soil-transmitted helminths. EBioMedicine (2017) 23:119-24. doi:10.1016/j.ebiom.2017.08.026

41. Elias D, Britton S, Aseffa A, Engers H, Akuffo H. Poor immunogenicity of BCG in helminth infected population is associated with increased in vitro TGF-beta production. Vaccine (2008) 26(31):3897-902. doi:10.1016/j. vaccine.2008.04.083

42. Andersen P, Doherty TM. The success and failure of BCG - implications for a novel tuberculosis vaccine. Nat Rev Microbiol (2005) 3(8):656-62. doi:10.1038/nrmicro1211

43. Dockrell HM, Smith SG. What have we learnt about BCG vaccination in the last 20 years? Front Immunol (2017) 8:1134. doi:10.3389/fimmu.2017.01134

44. Rhodes SJ, Sarfas C, Knight GM, White A, Pathan AA, McShane H, et al. Using data from macaques to predict gamma interferon responses after Mycobacterium bovis BCG vaccination in humans: a proof-of-concept study of immunostimulation/immunodynamic modeling methods. Clin Vaccine Immunol (2017) 24(3):e525-516. doi:10.1128/CVI.00525-16

45. Fletcher HA, Snowden MA, Landry B, Rida W, Satti I, Harris SA, et al. T-cell activation is an immune correlate of risk in BCG vaccinated infants. Nat Commun (2016) 7:11290. doi:10.1038/ncomms11290

46. Mangtani P, Nguipdop-Djomo P, Keogh RH, Sterne JAC, Abubakar I, Smith PG, et al. The duration of protection of school-aged BCG vaccination in England: a population-based case-control study. Int J Epidemiol (2017) 92(3):283-8. doi:10.1093/ije/dyx141

47. Hatherill M, Tait D, McShane H. Clinical testing of tuberculosis vaccine candidates. Microbiol Spectr (2016) 4(5):636-9.

48. McShane H, Jacobs WR, Fine PE, Reed SG, McMurray DN, Behr M, et al. BCG: myths, realities, and the need for alternative vaccine strategies. Tuberculosis (Edinb) (2012) 92(3):283-8. doi:10.1016/j.tube.2011.12.003

49. Ponnighaus JM, Fine PE, Sterne JA, Wilson RJ, Msosa E, Gruer PJ, et al. Efficacy of BCG vaccine against leprosy and tuberculosis in northern Malawi. Lancet (1992) 339(8794):636-9. doi:10.1016/0140-6736(92)90794-4

50. Barreto ML, Pereira SM, Pilger D, Cruz AA, Cunha SS, Sant'Anna C, et al. Evidence of an effect of BCG revaccination on incidence of tuberculosis in school-aged children in Brazil: second report of the BCG-REVAC cluster- randomised trial. Vaccine (2011) 29(31):4875-7. doi:10.1016/j.vaccine. 2011.05.023

51. Richardus RA, Butlin CR, Alam K, Kundu K, Geluk A, Richardus JH. Clinical manifestations of leprosy after BCG vaccination: an observational study in Bangladesh. Vaccine (2015) 33(13):1562-7. doi:10.1016/j. vaccine.2015.02.017

52. Richardus JH, Oskam L. Protecting people against leprosy: chemoprophylaxis and immunoprophylaxis. Clin Dermatol (2015) 33(1):19-25. doi:10.1016/j.clindermatol.2014.07.009

53. Kleinnijenhuis J, Quintin J, Preijers F, Benn CS, Joosten LA, Jacobs C, et al. Long-lasting effects of BCG vaccination on both heterologous Th1/Th17 responses and innate trained immunity. J Innate Immun (2014) 6(2):152-8. doi:10.1159/000355628

54. Polycarpou A, Holland MJ, Karageorgiou I, Eddaoudi A, Walker SL, Willcocks S, et al. Mycobacterium leprae activates toll-like receptor-4 signaling and expression on macrophages depending on previous bacillus Calmette-Guerin vaccination. Front Cell Infect Microbiol (2016) 6:72. doi:10.3389/fcimb.2016.00072

55. Geluk A, van Meijgaarden KE, Wilson L, Bobosha K, van der Ploeg-van Schip JJ, van den Eeden SJ, et al. Longitudinal immune responses and gene expression profiles in type 1 leprosy reactions. J Clin Immunol (2014) 34(2):245-55. doi:10.1007/s10875-013-9979-x

56. Convit J, Sampson C, Zúñiga M, Smith PG, Plata J, Silva J, et al. Immunoprophylactic trial with combined Mycobacterium leprae/BCG vaccine against leprosy: preliminary results. Lancet (1992) 339(8791):446-50. doi:10.1016/ 0140-6736(92)91056-E

57. Khullar G, Narang T, Sharma K, Saikia UN, Dogra S. Disseminated cutaneous BCG infection following BCG immunotherapy in patients with lepromatous leprosy. Lepr Rev (2015) 86(2):180-5.

58. Katoch K, Katoch VM, Natrajan M, Sreevatsa, Gupta UD, Sharma VD, et al. 10-12 years follow-up of highly bacillated BL/LL leprosy patients on combined chemotherapy and immunotherapy. Vaccine (2004) 22(27-28):3649-57. doi:10.1016/j.vaccine.2004.03.037

59. Frick M. The TB Prevention Pipeline. New York: (2017). Available from: www. pipelinereport.org

60. Wakhlu A, Gaur SP, Kaushal GP, Misra A, Asthana P, Sircar AR. Response of Mycobacterium habana vaccine in patients with lepromatous leprosy and their household contacts. A pilot clinical study. Lepr Rev (2001) 72(2):179-91. doi:10.5935/0305-7518.20010024

61. Karonga Prevention Trial Group. Randomised controlled trial of single BCG, repeated BCG, or combined BCG and killed Mycobacterium leprae vaccine for prevention of leprosy and tuberculosis in Malawi. Lancet (1996) 348(9019):17-24. doi:10.1016/S0140-6736(96)02166-6

62. Sharma P, Mukherjee R, Talwar GP, Sarathchandra KG, Walia R, Parida SK, et al. Immunoprophylactic effects of the anti-leprosy $\mathrm{Mw}$ vaccine in household contacts of leprosy patients: clinical field trials with a follow up of 8-10 years. Lepr Rev (2005) 76(2):127-43.

63. Truoc LV, Ly HM, Thuy NK, Trach DD, Stanford CA, Stanford JL. Vaccination against leprosy at Ben San Leprosy Centre, Ho Chi Minh City, Vietnam. Vaccine (2001) 19(25-26):3451-8. doi:10.1016/S0264-410X(01)00052-4

64. Duthie MS, Sampaio LH, Oliveira RM, Raman VS, O’Donnell J, Bailor HR, et al. Development and pre-clinical assessment of a $73 \mathrm{kD}$ chimeric fusion protein as a defined sub-unit vaccine for leprosy. Vaccine (2013) 31(5):813-9. doi:10.1016/j.vaccine.2012.11.073

65. Duthie MS, Coler RN, Laurance JD, Sampaio LH, Oliveira RM, Sousa AL, et al. Protection against Mycobacterium leprae infection by the ID83/GLA-SE and ID93/GLA-SE vaccines developed for tuberculosis. Infect Immun (2014) 82(9):3979-85. doi:10.1128/IAI.02145-14

66. IDRI. Leprosy Vaccine. (2017). Available from: http://www.idri.org/products/ vaccines/

67. Shen CF, Jacob D, Zhu T, Bernier A, Shao Z, Yu X, et al. Optimization and scale-up of cell culture and purification processes for production of an adenovirus-vectored tuberculosis vaccine candidate. Vaccine (2016) 34(29):3381-7. doi:10.1016/j.vaccine.2016.04.090

68. Satti I, Meyer J, Harris SA, Manjaly Thomas ZR, Griffiths K, Antrobus RD, et al. Safety and immunogenicity of a candidate tuberculosis vaccine MVA85A delivered by aerosol in BCG-vaccinated healthy adults: a phase 1, double-blind, randomised controlled trial. Lancet Infect Dis (2014) 14(10):939-46. doi:10.1016/S1473-3099(14)70845-X 
69. Minhinnick A, Satti I, Harris S, Wilkie M, Sheehan S, Stockdale L, et al. A first-in-human phase 1 trial to evaluate the safety and immunogenicity of the candidate tuberculosis vaccine MVA85A-IMX313, administered to BCG-vaccinated adults. Vaccine (2016) 34(11):1412-21. doi:10.1016/j. vaccine.2016.01.062

70. Stylianou E, Griffiths KL, Poyntz HC, Harrington-Kandt R, Dicks MD, Stockdale L, et al. Improvement of BCG protective efficacy with a novel chimpanzee adenovirus and a modified vaccinia Ankara virus both expressing Ag85A. Vaccine (2015) 33(48):6800-8. doi:10.1016/j.vaccine. 2015.10.017

71. Luabeya AK, Kagina BM, Tameris MD, Geldenhuys H, Hoff ST, Shi Z, et al. First-in-human trial of the post-exposure tuberculosis vaccine H56:IC31 in Mycobacterium tuberculosis infected and non-infected healthy adults. Vaccine (2015) 33(33):4130-40. doi:10.1016/j.vaccine.2015.06.051

72. Norrby M, Vesikari T, Lindqvist L, Maeurer M, Ahmed R, Mahdavifar S, et al. Safety and immunogenicity of the novel H4:IC31 tuberculosis vaccine candidate in BCG-vaccinated adults: two phase I dose escalation trials. Vaccine (2017) 35(12):1652-61. doi:10.1016/j.vaccine.2017.01.055

73. Baldwin SL, Reese VA, Huang PW, Beebe EA, Podell BK, Reed SG, et al. Protection and long-lived immunity induced by the ID93/GLA-SE vaccine candidate against a clinical Mycobacterium tuberculosis isolate. Clin Vaccine Immunol (2015) 23(2):137-47. doi:10.1128/CVI.00458-15

74. Gillard P, Yang PC, Danilovits M, Su WJ, Cheng SL, Pehme L, et al. Safety and immunogenicity of the M72/AS01E candidate tuberculosis vaccine in adults with tuberculosis: a phase II randomised study. Tuberculosis (Edinb) (2016) 100:118-27. doi:10.1016/j.tube.2016.07.005

75. Loxton AG, Knaul JK, Grode L, Gutschmidt A, Meller C, Eisele B, et al. Safety and immunogenicity of the recombinant Mycobacterium bovis BCG vaccine VPM1002 in HIV-unexposed newborn infants in South Africa. Clin Vaccine Immunol (2017) 24(2):e439-416. doi:10.1128/CVI.00439-16

76. Nell AS, D’Lom E, Bouic P, Sabate M, Bosser R, Picas J, et al. Safety, tolerability, and immunogenicity of the novel antituberculous vaccine RUTI: randomized, placebo-controlled phase II clinical trial in patients with latent tuberculosis infection. PLoS One (2014) 9(2):e89612. doi:10.1371/journal. pone.0089612

77. von Reyn CF, Lahey T, Arbeit RD, Landry B, Kailani L, Adams LV, et al. Safety and immunogenicity of an inactivated whole cell tuberculosis vaccine booster in adults primed with BCG: a randomized, controlled trial of DAR-901. PLoS One (2017) 12(5):e0175215. doi:10.1371/journal. pone. 0175215

78. Huang CY, Hsieh WY. Efficacy of Mycobacterium vaccae immunotherapy for patients with tuberculosis: a systematic review and meta-analysis. Hum Vaccin Immunother (2017) 13(9):1960-71. doi:10.1080/21645515. 2017.1335374

79. Spertini F, Audran R, Chakour R, Karoui O, Steiner-Monard V, Thierry AC, et al. Safety of human immunisation with a live-attenuated Mycobacterium tuberculosis vaccine: a randomised, double-blind, controlled phase I trial. Lancet RespirMed(2015) 3(12):953-62. doi:10.1016/S2213-2600(15)00435-X

80. Orme IM. Tuberculosis vaccine types and timings. Clin Vaccine Immunol (2015) 22(3):249-57. doi:10.1128/CVI.00718-14

81. Duthie MS, Gillis TP, Reed SG. Advances and hurdles on the way toward a leprosy vaccine. Hum Vaccin (2011) 7(11):1172-83. doi:10.4161/hv.7.11.16848

82. Kumar S. India resurrects forgotten leprosy vaccine. Science (2017) 356(6342):999. doi:10.1126/science.356.6342.999

83. Richardus RA, Alam K, Pahan D, Feenstra SG, Geluk A, Richardus JH. The combined effect of chemoprophylaxis with single dose rifampicin and immunoprophylaxis with BCG to prevent leprosy in contacts of newly diagnosed leprosy cases: a cluster randomized controlled trial (MALTALEP study). BMC Infect Dis (2013) 13:456. doi:10.1186/1471-2334-13-456

84. Tameris MD, Hatherill M, Landry BS, Scriba TJ, Snowden MA, Lockhart $\mathrm{S}$, et al. Safety and efficacy of MVA85A, a new tuberculosis vaccine, in infants previously vaccinated with BCG: a randomised, placebo-controlled phase 2b trial. Lancet (2013) 381(9871):1021-8. doi:10.1016/ S0140-6736(13)60177-4

85. Pathan AA, Minassian AM, Sander CR, Rowland R, Porter DW, Poulton ID, et al. Effect of vaccine dose on the safety and immunogenicity of a candidate TB vaccine, MVA85A, in BCG vaccinated UK adults. Vaccine (2012) 30(38):5616-24. doi:10.1016/j.vaccine.2012.06.084
86. Ottenhoff TH, Verreck FA, Lichtenauer-Kaligis EG, Hoeve MA, Sanal O, van Dissel JT. Genetics, cytokines and human infectious disease: lessons from weakly pathogenic mycobacteria and salmonellae. Nat Genet (2002) 32(1):97-105. doi:10.1038/ng0902-97

87. Flynn JL, Chan J, Triebold KJ, Dalton DK, Stewart TA, Bloom BR. An essential role for interferon gamma in resistance to Mycobacterium tuberculosis infection. J Exp Med (1993) 178(6):2249-54. doi:10.1084/jem.178.6.2249

88. Ottenhoff TH, de Boer T, Verhagen CE, Verreck FA, van Dissel JT. Human deficiencies in type 1 cytokine receptors reveal the essential role of type 1 cytokines in immunity to intracellular bacteria. Microbes Infect (2000) 2(13):1559-66. doi:10.1016/S1286-4579(00)01312-5

89. Lawn SD, Myer L, Edwards D, Bekker LG, Wood R. Short-term and longterm risk of tuberculosis associated with CD4 cell recovery during antiretroviral therapy in South Africa. AIDS (2009) 23(13):1717-25. doi:10.1097/ QAD.0b013e32832d3b6d

90. Green AM, Difazio R, Flynn JL. IFN-gamma from CD4 T cells is essential for host survival and enhances CD8 T cell function during Mycobacterium tuberculosis infection. JImmunol (2013) 190(1):270-7. doi:10.4049/ jimmunol.1200061

91. Nath I. A vaccine for leprosy. Nat Med (1998) 4(5):548-50. doi:10.1038/ nm0598-548

92. Geluk A. Biomarkers for leprosy: would you prefer T (cells)? Lepr Rev (2013) 84(1):3-12.

93. Araujo S, Rezende MM, Sousa DC, Rosa MR, Santos DC, Goulart LR, et al. Risk-benefit assessment of Bacillus Calmette-Guerin vaccination, antiphenolic glycolipid I serology, and Mitsuda test response: 10-year follow-up of household contacts of leprosy patients. Rev Soc Bras Med Trop (2015) 48(6):739-45. doi:10.1590/0037-8682-0245-2015

94. Boer MC, Prins C, van Meijgaarden KE, van Dissel JT, Ottenhoff TH, Joosten SA. Mycobacterium bovis BCG vaccination induces divergent proinflammatory or regulatory $\mathrm{T}$ cell responses in adults. Clin Vaccine Immunol (2015) 22(7):778-88. doi:10.1128/CVI.00162-15

95. Kagina BM, Abel B, Scriba TJ, Hughes EJ, Keyser A, Soares A, et al. Specific $\mathrm{T}$ cell frequency and cytokine expression profile do not correlate with protection against tuberculosis after bacillus Calmette-Guerin vaccination of newborns. Am J Respir Crit Care Med (2010) 182(8):1073-9. doi:10.1164/ rccm.201003-0334OC

96. Fonseca AB, Simon MD, Cazzaniga RA, de Moura TR, de Almeida RP, Duthie MS, et al. The influence of innate and adaptative immune responses on the differential clinical outcomes of leprosy. Infect Dis Poverty (2017) 6(1):5. doi:10.1186/s40249-016-0229-3

97. Scriba TJ, Coussens AK, Fletcher HA. Human immunology of tuberculosis. Microbiol Spectr (2017) 4(4). doi:10.1128/microbiolspec.TBTB20016-2016

98. Mayosi BM, Ntsekhe M, Bosch J, Pogue J, Gumedze F, Badri M, et al. Rationale and design of the investigation of the management of pericarditis (IMPI) trial: a 2 × 2 factorial randomized double-blind multicenter trial of adjunctive prednisolone and Mycobacterium w immunotherapy in tuberculous pericarditis. Am Heart J (2013) 165(2):109.e-15.e. doi:10.1016/j. ahj.2012.08.006

99. Valdes I, Montoro E, Mata-Espinoza D, Asin O, Barrios-Payan J, FranciscoCruz A, et al. Immunogenicity and protection conferred by Mycobacterium habana in a murine model of pulmonary tuberculosis. Tuberculosis (Edinb) (2014) 94(1):65-72. doi:10.1016/j.tube.2013.08.011

100. Cole ST, Eiglmeier K, Parkhill J, James KD, Thomson NR, Wheeler PR, et al. Massive gene decay in the leprosy bacillus. Nature (2001) 409(6823):1007-11. doi:10.1038/35059006

101. Sorensen AL, Nagai S, Houen G, Andersen P, Andersen AB. Purification and characterization of a low-molecular-mass T-cell antigen secreted by Mycobacterium tuberculosis. Infect Immun (1995) 63(5):1710-7.

102. Daniel TM, Ferguson LE. Purification and characterization of two proteins from culture filtrates of Mycobacterium tuberculosis H(37)Ra strain. Infect Immun (1970) 1(2):164-8.

103. Kremer L, Maughan WN, Wilson RA, Dover LG, Besra GS. The M. tuberculosis antigen 85 complex and mycolyltransferase activity. Lett Appl Microbiol (2002) 34(4):233-7. doi:10.1046/j.1472-765x.2002.01091.x

104. Skjot RL, Oettinger T, Rosenkrands I, Ravn P, Brock I, Jacobsen S, et al. Comparative evaluation of low-molecular-mass proteins from 
Mycobacterium tuberculosis identifies members of the ESAT-6 family as immunodominant T-cell antigens. Infect Immun (2000) 68(1):214-20. doi:10.1128/IAI.68.1.214-220.2000

105. Ottenhoff TH, Doherty TM, van Dissel JT, Bang P, Lingnau K, Kromann I, et al. First in humans: a new molecularly defined vaccine shows excellent safety and strong induction of long-lived Mycobacterium tuberculosis-specific Th1-cell like responses. Hum Vaccin (2010) 6(12):1007-15. doi:10.4161/ hv.6.12.13143

106. Olsen AW, Williams A, Okkels LM, Hatch G, Andersen P. Protective effect of a tuberculosis subunit vaccine based on a fusion of antigen $85 \mathrm{~B}$ and ESAT- 6 in the aerosol guinea pig model. Infect Immun (2004) 72(10):6148-50. doi:10.1128/IAI.72.10.6148-6150.2004

107. Langermans JA, Doherty TM, Vervenne RA, van der Laan T, Lyashchenko K, Greenwald R, et al. Protection of macaques against Mycobacterium tuberculosis infection by a subunit vaccine based on a fusion protein of antigen 85B and ESAT-6. Vaccine (2005) 23(21):2740-50. doi:10.1016/j. vaccine.2004.11.051

108. van Dissel JT, Joosten SA, Hoff ST, Soonawala D, Prins C, Hokey DA, et al. A novel liposomal adjuvant system, CAF01, promotes long-lived Mycobacterium tuberculosis-specific T-cell responses in human. Vaccine (2014) 32(52):7098-107. doi:10.1016/j.vaccine.2014.10.036

109. van Dissel JT, Soonawala D, Joosten SA, Prins C, Arend SM, Bang P, et al. Ag85B-ESAT-6 adjuvanted with IC31(R) promotes strong and long-lived Mycobacterium tuberculosis specific $\mathrm{T}$ cell responses in volunteers with previous BCG vaccination or tuberculosis infection. Vaccine (2011) 29(11):2100-9. doi:10.1016/j.vaccine.2010.12.135

110. Lenz N, Schindler T, Kagina BM, Zhang JD, Lukindo T, Mpina M, et al. Antiviral innate immune activation in HIV-infected adults negatively affects H1/IC31-induced vaccine-specific memory CD4+ T cells. Clin Vaccine Immunol (2015) 22(7):688-96. doi:10.1128/CVI.00092-15

111. Reither K, Katsoulis L, Beattie T, Gardiner N, Lenz N, Said K, et al. Safety and immunogenicity of H1/IC31(R), an adjuvanted TB subunit vaccine, in HIV-infected adults with CD4+ lymphocyte counts greater than 350 cells/mm3: a phase II, multi-centre, double-blind, randomized, placebocontrolled trial. PLoS One (2014) 9(12):e114602. doi:10.1371/journal. pone. 0114602

112. Parkash O, Pandey R, Kumar A, Kumar A. Performance of recombinant ESAT-6 antigen (ML0049) for detection of leprosy patients. Lett Appl Microbiol (2007) 44(5):524-30. doi:10.1111/j.1472-765X.2006.02099.x

113. Spencer JS, Kim HJ, Wheat WH, Chatterjee D, Balagon MV, Cellona RV, et al. Analysis of antibody responses to Mycobacterium leprae phenolic glycolipid I, lipoarabinomannan, and recombinant proteins to define disease subtype-specific antigenic profiles in leprosy. Clin Vaccine Immunol (2011) 18(2):260-7. doi:10.1128/CVI.00472-10

114. Geluk A, van Meijgaarden KE, Franken KL, Subronto YW, Wieles B, Arend SM, et al. Identification and characterization of the ESAT-6 homologue of Mycobacterium leprae and T-cell cross-reactivity with Mycobacterium tuberculosis. Infect Immun (2002) 70(5):2544-8. doi:10.1128/ IAI.70.5.2544-2548.2002

115. Gillis TP, Tullius MV, Horwitz MA. rBCG30-induced immunity and cross-protection against Mycobacterium leprae challenge are enhanced by boosting with the Mycobacterium tuberculosis 30-kilodalton antigen 85B. Infect Immun (2014) 82(9):3900-9. doi:10.1128/IAI.01499-13

116. Franken KL, Hiemstra HS, van Meijgaarden KE, Subronto Y, den Hartigh J, Ottenhoff TH, et al. Purification of his-tagged proteins by immobilized chelate affinity chromatography: the benefits from the use of organic solvent. Protein Expr Purif (2000) 18(1):95-9. doi:10.1006/prep.1999.1162

117. Geluk A, van den Eeden SJ, Dijkman K, Wilson L, Kim HJ, Franken KL, et al. ML1419c peptide immunization induces Mycobacterium lepraespecific HLA- ${ }^{*} 0201$-restricted CTL in vivo with potential to kill live mycobacteria. J Immunol (2011) 187(3):1393-402. doi:10.4049/jimmunol.1100980

118. Geluk A, Klein MR, Franken KL, van Meijgaarden KE, Wieles B, Pereira KC, et al. Postgenomic approach to identify novel Mycobacterium leprae antigens with potential to improve immunodiagnosis of infection. Infect Immun (2005) 73(9):5636-44. doi:10.1128/IAI.73.9.5636-5644.2005

119. Commandeur S, van den Eeden SJ, Dijkman K, Clark SO, van Meijgaarden KE, Wilson L, et al. The in vivo expressed Mycobacterium tuberculosis (IVE-TB) antigen Rv2034 induces CD4(+) T-cells that protect against pulmonary infection in HLA-DR transgenic mice and guinea pigs. Vaccine (2014) 32(29):3580-8. doi:10.1016/j.vaccine.2014.05.005

120. Geluk A, van den Eeden SJ, van Meijgaarden KE, Dijkman K, Franken KL, Ottenhoff TH. A multistage-polyepitope vaccine protects against Mycobacterium tuberculosis infection in HLA-DR3 transgenic mice. Vaccine (2012) 30(52):7513-21. doi:10.1016/j.vaccine.2012.10.045

121. Truman RW, Krahenbuhl JL. Viable M. leprae as a research reagent. Int J Lepr Other Mycobact Dis (2001) 69(1):1-12.

122. Truman RW, Andrews PK, Robbins NY, Adams LB, Krahenbuhl JL, Gillis TP. Enumeration of Mycobacterium leprae using real-time PCR. PLoS Negl Trop Dis (2008) 2(11):e328. doi:10.1371/journal.pntd.0000328

123. Coppola M, van Meijgaarden KE, Franken KL, Commandeur S, Dolganov G, Kramnik I, et al. New genome-wide algorithm identifies novel in-vivo expressed Mycobacterium tuberculosis antigens inducing human T-cell responses with classical and unconventional cytokine profiles. Sci Rep (2016) 6:37793. doi:10.1038/srep37793

124. Singh P, Cole ST. Mycobacterium leprae: genes, pseudogenes and genetic diversity. Future Microbiol (2011) 6(1):57-71. doi:10.2217/fmb.10.153

125. Akinola RO, Mazandu GK, Mulder NJ. A quantitative approach to analyzing genome reductive evolution using protein-protein interaction networks: a case study of Mycobacterium leprae. Front Genet (2016) 7:39. doi:10.3389/ fgene.2016.00039

Conflict of Interest Statement: The authors declare that the research was conducted in the absence of any commercial or financial relationships that could be construed as a potential conflict of interest.

Copyright (c) 2018 Coppola, van den Eeden, Robbins, Wilson, Franken, Adams, Gillis, Ottenhoff and Geluk. This is an open-access article distributed under the terms of the Creative Commons Attribution License (CC BY). The use, distribution or reproduction in other forums is permitted, provided the original author(s) and the copyright owner are credited and that the original publication in this journal is cited, in accordance with accepted academic practice. No use, distribution or reproduction is permitted which does not comply with these terms. 